\title{
The Optimization Problem of Product Mix and Linear Programming Applications: Case Study in the Apparel Industry
}

\section{OPEN ACCESS}

Citation: Woubante G. W. (2017) The Optimization Problem of Product Mix and Linear Programming Applications: Case Study in the Apparel Industry. Open Science Journal 2(2).

Received: $6^{\text {th }}$ January, 2017

Accepted: $20^{\text {th }}$ March, 2017

Published: $19^{\text {th }}$ June, 2017

Copyright:@ 2017 This is an open access article under the terms of the Creative Commons Attribution License, which permits unrestricted use, distribution, and reproduction in any medium, provided the original author and source are credited.

Funding: The author(s) received no specific funding for this work

Competing Interests: The author have declared that no competing interests exists.

\author{
Gera Workie Woubante* \\ Bahir Dar University, Bahir Dar, Ethiopia \\ *Corresponding Author: Gera Workie Woubante: likeredg@gmail.com
}

\section{Abstract}

Industrial development strategy is characterized by the efficient use of resources at every production stage. The analysis and efficient utilization of resources are made sustainable by effective management decision making techniques employed in the industry. A quantitative decision making tool called linear programming can be used for the optimization problem of product mix. Understanding the concept behind the optimization problem of product mix is essential to the success of the industry for meeting customer needs, determining its image, focusing on its core business, and inventory management. Apparel manufacturing firms profit mainly depends on the proper allocation and usage of available production time, material, and labor resources. This paper considers an apparel industrial unit in Ethiopia as a case study. The monthly held resources, product volume, and amount of resources used to produce each unit of product and profit per unit for each product have been collected from the company. The data gathered was used to estimate the parameters of the linear programming model. The model was solved using LINGO 16.0 software. The findings of the study show that the profit of the company can be improved by $59.84 \%$, that is, the total profit of Birr 465,456 per month can be increased to Birr 777,877.3 per month by applying linear programming models if customer orders have to be satisfied. The profit of the company can be improved by $7.22 \%$ if the linear programming formulation does not need to consider customer orders. 
Keywords: Apparel sector, Linear programming, Lingo, Optimal, Product mix.

\section{Introduction}

Companies in the world, including Ethiopia, have faced problems on optimization of production inputs. A company's endurance in a competitive market closely depends on its ability to produce the highest quality products at the lowest possible cost (Kumar, 2010). Ezema and Amakom (2012) emphasized that organizations in the world are challenged by shortages of production inputs and low capacity utilization that can consequently lead to low production outputs. Companies have to create a management style to guide their performances in processing and resource utilization. Apparel manufacturing firm profit is significantly affected by the cost of resources and resource utilization (Arefayne and Pal, 2014). Linear programming is an operational research technique used to allocate optimally production resources for a firm's best practices. It is the most widely used tool (Reeb and Leavengood, 1998) to determine optimal resource utilization. Different products require different amount of production resources having different costs and revenues at different stages of production. Thus, the linear programming problem (LPP) technique will be used to determine the product mix that will maximize the total profit at a specified time. It is the best method for determining an optimal solution among alternatives to meet a specified objective function limited by various constraints and restrictions (Shaheen and Ahmad, 2015). As Reeb and Leavengood (1998) stated, it is a planning process that allocates resources-labor, materials, machines, and capital - in the best possible way so that costs are minimized or profits are maximized. The LPP then becomes a problem of allocating scarce resources to products in a manner such that profits are at a maximum and/or costs are at a minimum (Yahya, 2004). However, managers in companies create gaps in adopting the method to allocate scarce resources among operations and providing quantitative analysis for each production period due to lack of awareness.

An industry consists of a number of product lines, which are groups of items featuring similar characteristics. Together, these product lines comprise the product mix, which is the total assortment of products the company offers. Product mix determination is essential to the success of the industry for a number of important reasons. First, crafting the proper assortment of products provides the best opportunity of meeting customers' needs. The customers come to rely on the industry as their primary resource. By carefully monitoring product mix and seeking feedback from customers, the firm will be able to make adjustments as the needs of customers change over time. Second, it shapes the image of the industry and its brand to maintain consistency in the eyes of the target market. Third, the industry stays focused on its core business. The industry may be tempted to add more product lines in an effort to reach more customers. By doing so, it could be in danger of adding products that appeal only to a fraction of its customer base while alienating the core customers. As a rule, core customers are the ones who provide about 80 percent of the business, so 
these customers have to be kept in mind when contemplating changes to the product mix. Finally, the industry probably faces limitations regarding the number of products it is able to offer. By focusing on providing the optimum product mix for its customers, it will be able to weed out slow sellers and make room for more appealing items.

In Ethiopia, the apparel sector is considered as one of the priority areas of the government's industrial development strategy (ETIDI, 2014). However, the sector has faced many challenges to determine product mix. It is confronted with inefficient utilization of resources that makes it difficult to ensure the optimal product mix for maximal profit, which would also fulfill customer needs. As noted by Samuel (2012), to modernize the apparel sector, performance was insignificant. Thus, apparel manufacturing companies must adopt operations research techniques to enhance best resource utilization that would result in optimal product mix and total profit. Thus, this paper focuses on product mix determination based on efficient resource utilization for the Ethiopian apparel sector by considering a garment factory in Ethiopia as a case company. The issue addressed here was to determine the product mix for optimal profit with available resources, using the linear programming technique LINGO 16.0, that the case company should produce for men wear: Polo shirt, basic T-shirt, mock neck T-shirt, short pants, and singlet. In line with this, the objective of the study was to suggest linear programming as a decision tool to determine the optimal product mix for maximum profit with available resources in the apparel sector.

\section{Methodology}

The data collection procedure was quantitative in nature and relied on faceto-face interviews with members of the management and line supervisors in accordance with existing records and merely amended to finalize the concepts relevant to the resources held and consumed and the production volume of each product in the case company. The relevant information on the amount of resources used per unit of each product during the month is summarized in Table 1.

Table 1: Resources needed per unit of product.

\begin{tabular}{|c|c|c|c|c|c|c|c|}
\hline \multirow[b]{2}{*}{$\begin{array}{ll}\text { Products } & \text { (T- } \\
\text { Shirts } & \text { and } \\
\text { Pants) } & \end{array}$} & \multicolumn{7}{|c|}{ Resource used per unit of products } \\
\hline & 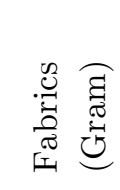 & 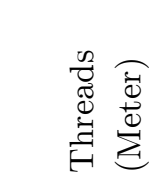 & 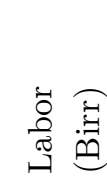 & 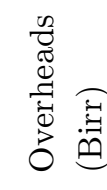 & 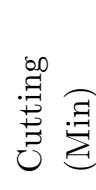 & 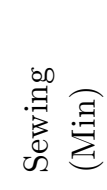 & 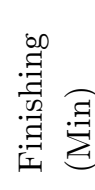 \\
\hline Polo T-shirts & 315 & 230 & 11.6 & 30.6 & 1.8 & 22.7 & 2 \\
\hline Basic T-shirts & 200 & 110 & 5 & 19.1 & 1.1 & 5.4 & 1.3 \\
\hline $\begin{array}{l}\text { Mock Neck T- } \\
\text { shirts }\end{array}$ & 195 & 140 & 6.3 & 20.1 & 1.7 & 10.4 & 1.9 \\
\hline Singlets & 180 & 100 & 4.15 & 16.5 & 1.1 & 4.5 & 1.3 \\
\hline
\end{tabular}




\begin{tabular}{|l|l|l|l|l|l|l|l|}
\hline Short Pants & 280 & 200 & 7.5 & 37.5 & 2.6 & 20.1 & 2.6 \\
\hline
\end{tabular}

Source: 2015 Resources used per unit of products of the case apparel company

The ability to use resources (resource utilization) was recorded as the major constraints in the case apparel manufacturing unit. Seven constraints (fabrics, thread, labor, overheads, cutting, sewing, and finishing time) and five costumer orders for T-shirt products have been identified. Out of the resources used by the case apparel company, the major items held and consumed are shown in Table 2.

Table 2: Average monthly resources held and consumed in quantity/value terms in Birr.

\begin{tabular}{|l|l|l|l|}
\hline \multicolumn{4}{|c|}{ Resources } \\
\hline Resource Type & Measurement Unit & Held Value & Consumption Value \\
\hline Fabrics & $\mathrm{kg}$ & 38,665 & $20,526.871$ \\
\hline Threads & Meter & $26,638,120$ & 132,887 \\
\hline Labor & Birr & $1,009,008$ & 590,765 \\
\hline Overheads & Birr & $4,979,414$ & $2,116,525$ \\
\hline Cutting & $\mathrm{h}$ & 5,770 & $2,320.42$ \\
\hline Sewing & $\mathrm{h}$ & 44,505 & $16,705.7$ \\
\hline Finishing & $\mathrm{h}$ & 6,195 & 2,583 \\
\hline
\end{tabular}

The demand and profit earned from each product during the month for the case apparel company are depicted in Table 3.

Table 3: Demand and profit earned.

\begin{tabular}{|c|c|c|c|c|c|c|}
\hline & 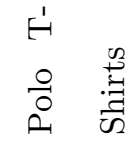 & 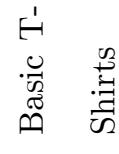 & 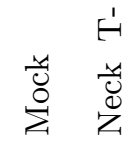 & 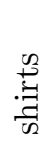 & $\begin{array}{l}\frac{0}{0} \\
0 \\
0 \\
0 \\
0\end{array}$ & $\begin{array}{l}\overrightarrow{0} \\
\frac{0}{0} \\
\text { n }\end{array}$ \\
\hline Demand & 15886 & 23916 & 13319 & & 25667 & 12864 \\
\hline Profit per Unit & 4.22 & 3.62 & 3.43 & & 3.10 & 6.75 \\
\hline
\end{tabular}

\section{Model Formulation}

In formulating a given decision problem in mathematical form, one should try to comprehensively understand the problem (i.e., formulate a mental model) by carefully reading and re-reading the problem statement. While trying to understand the problem, the decision maker may decide that the model consists of linear relationships representing a firm's objectives and resource constraints. However, the way we approach the problem is the same for a wide variety of decision making problems, and the size and complexity of the problem may differ. An LPP model consists of the following parameters: 
$>$ Decision variables that are mathematical symbols representing levels of activity of an operation.

$>$ The objective function that is a linear mathematical relationship describing an objective of the firm, in terms of decision variables, that is to be maximized or minimized.

> Constraints that are restrictions placed on the firm by the operating environment situated in linear relationships with the decision variables.

$>$ Parameters/cost coefficients that are numerical coefficients and constants used in the objective function and constraint equations.

\section{Basic Assumptions (Properties) of LPP}

Technically, there are five additional requirements of an LPP:

1. We assume that conditions of certainty exist; that is, the numbers in the objective and constraints are known with certainty and do not change during the period being studied.

2. We also assume that proportionality exists in the objective and constraints. This means that if production of 1 unit of a product uses $3 \mathrm{~h}$ of a particular scarce resource, then making 10 units of that product uses $30 \mathrm{~h}$ of the resource.

3. The third technical assumption deals with additivity, meaning that the total of all activities equals the sum of the individual activities.

4. We make the divisibility assumption that solutions need not be in whole numbers (integers). Instead, they are divisible and may take any fractional value.

5. Finally, we assume that all answers or variables are nonnegative. Negative values of physical quantities are impossible; we simply cannot produce a negative number of textile products.

\section{Linear Programming Model Formulation Steps}

In this section, we consider the steps involved in the mathematical formulation of the problem. LPP is a collection of the objective function, the set of constraints, and the set of nonnegative constraints.

Step 1: Clearly define the decision variables of the problem, $X=\left(x_{1}, x_{2}, \ldots, x_{n}\right)$.

Step 2: Write the objective function as a linear combination of the decision variables, $Z=f(X)$.

Step 3: Formulating the constraints of the problem as a linear combination of the decision variables.

\section{General Form of the Linear Programming Model}

In general, if $C=\left(c_{1}, c_{2}, \ldots, c_{n}\right)$ is a tuple of real numbers, then the function $f$ of real variables $X=\left(x_{1}, x_{2}, \ldots, x_{n}\right)$ defined by

$$
f(X)=c_{1} x_{1}+c_{2} x_{2}+\ldots+c_{n} x_{n}
$$


is known as a linear function. If $g$ is a linear function and $b=\left(b_{1}, b_{2}, \ldots, b_{n}\right)$ is a tuple of real numbers, then $g(x)=b$ is called a linear equation, whereas $g(x)(\leq$, $\geq) b$ is called a linear inequality. A linear constraint is one that is either a linear equation or a linear inequality. A linear programming problem (LPP) is one which optimizes (maximizes or minimizes) a linear function subject to a finite collection of linear constraints. Formally, any LPP having $n$ decision variables can be written in the following form:

Optimize $Z=\sum_{j=1}^{n} C_{j} X_{j}$

\section{Subject to}

$$
\begin{gathered}
\sum_{i=1}^{m} a_{i j} X_{j}(\leq,=, \geq) b_{i}, i=1,2, \ldots, m \\
X_{j} \geq 0, j=1,2, \ldots, n
\end{gathered}
$$

where $C_{j}, a_{i j}, b_{i}$ are constants.

Common terminology for the aforementioned linear programming model can now be summarized as follows. The function, being optimized (maximized or minimized), is referred to as the objective function. The restrictions normally are referred to as constraints. The first $m$ constraints (those with a function of all the variables, on the left-hand side) are called functional constraints (or structural constraints). Similarly, the $X_{j} \geq 0, j=1,2, \ldots, n$ restrictions are called non-negativity constraints (or non-negativity conditions) and the aim is to find the values of the variables $X_{j}$. Any vector $X_{j}$, satisfying the constraint of the LPP is called a feasible solution of the problem (Fogiel, 1996; Schulze, 1998; Chinneck, 2000). In this paper, we use the following terminology for the solution. A feasible solution is a solution for which all the constraints are satisfied. An infeasible solution is a solution for which at least one constraint is violated. The problem is to find the values of the decision variables $X_{j}$ that maximize the objective function $Z$ subject to the $m$ constraints and the non-negativity restriction on the $X_{j}$ variable. The resulting set of decision variables that maximize the objective function is called the optimal solution.

\section{Results and Discussion}

The information collected from the case company in addition to the sales and other operating data was analyzed to provide estimates for LPP model parameters. To set up the model, the first level decision variables on the volume of products to be produced were set.

$x_{1}=$ number of Polo T-shirts

$x_{2}=$ number of basic T-shirts 
$x_{3}=$ number of mock neck T-shirts

$x_{4}=$ number of singlets

$x_{5}=$ number of short pants

$Z=$ total profit during the month

Now, the linear programming model, maximizing the total profit is:

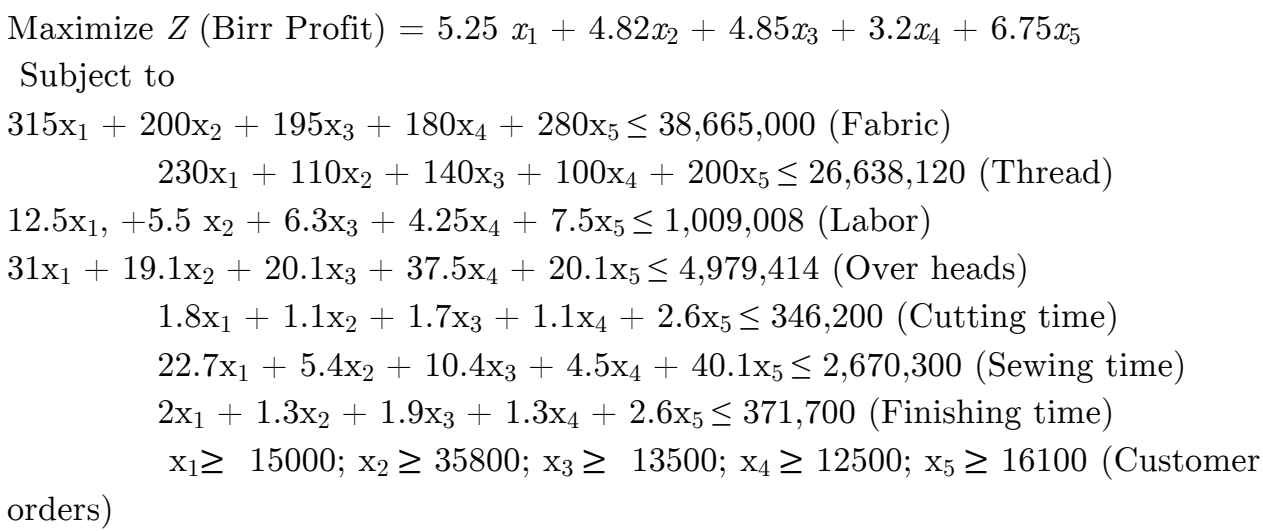

\section{Model Solution}

A powerful linear programming problem solving technique is the simplex method. Among the various software packages, LINGO 16.0 software was used to hold the simplex procedures. The global optimal solution report for this model is as follows.

Objective value:

777877.3

Infeasibilities:

0.000000

Total solver iterations:

Elapsed run time seconds:

Model class:

LP

Total variables:

6

Nonlinear variables: $\quad 0$

Integer variables: $\quad 0$

Total constraints: $\quad 14$

Nonlinear constraints: $\quad 0$

Total nonzeros: $\quad 47$

Nonlinear nonzeros: 0

Variable

$\underline{\text { Reduced Cost }}$

$\begin{array}{rrr}Z & 777877.3 & 0.000000 \\ x_{1} & 15000.00 & 0.000000 \\ x_{2} & 102287.8 & 0.000000 \\ x_{3} & 13500.00 & 0.000000 \\ x_{4} & 12500.00 & 0.000000 \\ x_{5} & 16100.00 & 0.000000\end{array}$




\begin{tabular}{ccc} 
Row & Slack or Surplus Dual Price \\
\hline 1 & 777877.3 & 1.000000 \\
2 & 0.000000 & 1.000000 \\
3 & 4091936. & 0.000000 \\
4 & 5576460. & 0.000000 \\
5 & 0.000000 & 0.8763636 \\
6 & 1897867. & 0.000000 \\
7 & 128123.4 & 0.000000 \\
8 & 1246957. & 0.000000 \\
9 & 124965.8 & 0.000000 \\
10 & 0.000000 & 5.704545 \\
11 & 66487.82 & 0.000000 \\
12 & 0.000000 & 0.6710909 \\
13 & 0.000000 & 0.5245455 \\
14 & 0.000000 & 0.3227273
\end{tabular}

Here, there was a difference between the LPP solutions obtained to satisfy customer orders using LINGO 16.0 and actual production in Table 3 . In the former case, the product mix was Polo T-shirts, basic T-shirts, Mock neck Tshirts, singlets, and short pants with volumes of 15,000.00, 102,287.8, 13,500.00, $12,500.00$, and 16,100.00 respectively, and with a total profit of Birr 777,877.3 per month upon selling. In the latter case, the product mix was Polo T-shirts, basic T-shirts, mock neck T-shirts, singlets, and short pants with optimal volumes of $15,000.00,35,800.00,13,500.00,12500.00$, and 16,100.00 respectively, and with a total profit of Birr 465,456 per month. At optimality, resources consumed by the LINGO 16.0 software result were compared with the customer orders during the month. In this case, the profit of the company could be improved by $59.84 \%$.

From Table 2, the monthly consumption values of customer orders for each available resource were gathered from the company's records. These consumption values and LPP consumption values are summarized in Table 4. The ratios of monthly consumption of the resources held were calculated to find the percentage usage by each T-shirt style.

Table 4: Monthly consumption by LPP techniques and customer order production.

\begin{tabular}{|c|c|c|c|c|c|c|}
\hline \multicolumn{3}{|c|}{ Resources Held per Month } & \multicolumn{2}{|c|}{$\begin{array}{l}\text { Monthly Resources } \\
\text { Consumption }\end{array}$} & \multicolumn{2}{|c|}{$\begin{array}{l}\text { Percentage }(\%) \text { of } \\
\text { Usage }\end{array}$} \\
\hline & & & \multirow{2}{*}{$\begin{array}{l}\text { Customer } \\
\text { order }\end{array}$} & \multirow{2}{*}{ LPP } & \multirow{2}{*}{$\begin{array}{l}\text { Customer } \\
\text { order }\end{array}$} & \multirow{2}{*}{ LPP } \\
\hline Туре & Unit & Value & & & & \\
\hline Fabrics & Gram & 38665000 & $20,526,871$ & 34573064 & 53.09 & 89.42 \\
\hline Threads & Meter & $26,638,120$ & $13,288,700$ & 21061660 & 49.89 & 79.07 \\
\hline Labor & Birr & $1,009,008$ & 590,765 & $1,009,008$ & 58.55 & 100 \\
\hline
\end{tabular}


Research Article

\begin{tabular}{|l|l|l|l|l|l|l|}
\hline Overheads & Birr & 4979414 & $2,116,525$ & 3081547 & 42.51 & 61.89 \\
\hline Cutting & Min & 346302 & 139,225 & 218076.2 & 40.20 & 62.97 \\
\hline Sewing & Min & 2670336 & $1,002,344$ & 1423343 & 37.54 & 53.30 \\
\hline Finishing & Min & 371628 & 154,982 & 246734.2 & 41.70 & 66.38 \\
\hline
\end{tabular}

The study shows that the LPP resource utilization of fabrics, threads, labor, overheads, cutting, sewing, and finishing can be significantly improved to $89.42 \%$, $79.07 \%, 100 \%, 61.89 \%, 62.97 \%, 53.30 \%$, and $66.38 \%$ respectively. Thus, Figure 1 shows that production based on customer orders lead to inefficient resource utilization since most of the resources are idle.

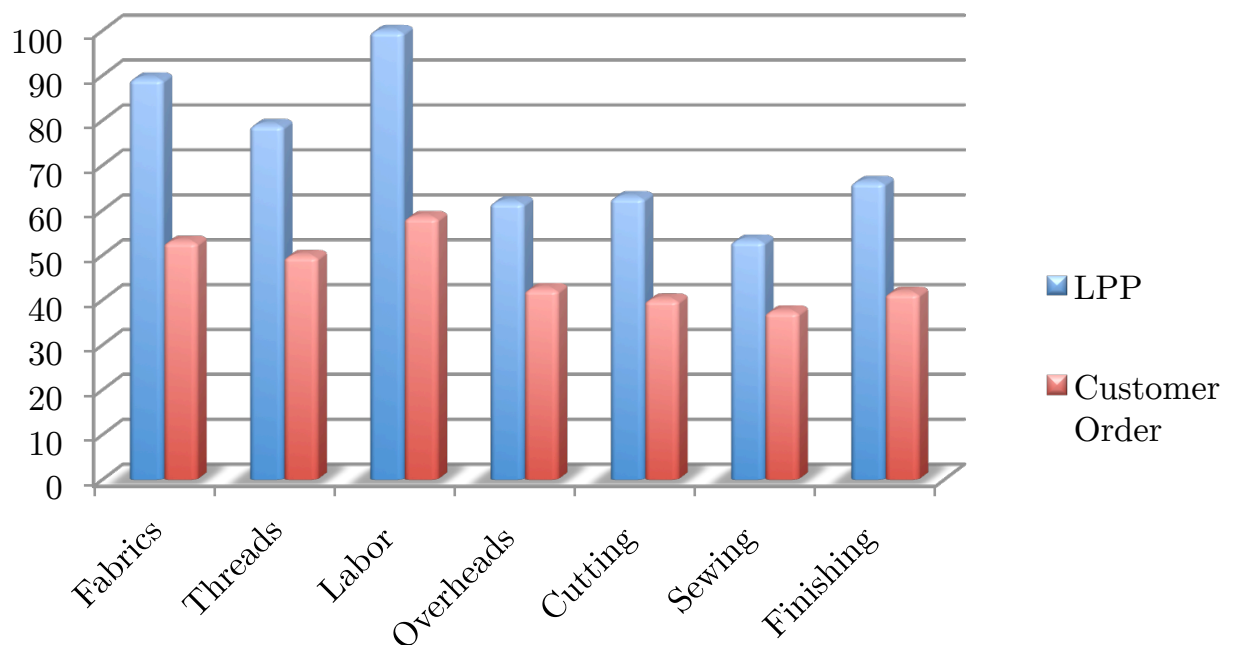

Figure 1: Comparison of customer order and LPP production resources utilization.

Here, an analysis has been made without considering customer orders to develop an LPP model using monthly consumption of resources. The monthly consumption of each resource values are given under the left-hand side column in Table 2, which can be used as required for the constraints.

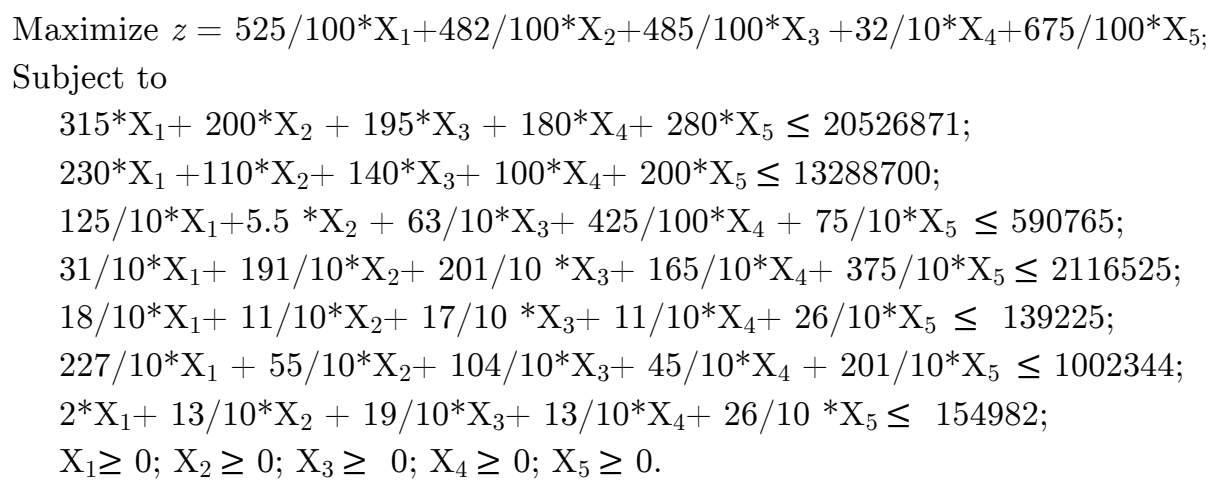


The optimal solution values of the decision variables were obtained using the LINGO $16.0 \mathrm{~s}$ software. Table 5 shows the monthly product mix of the actual system obtained from the factory and that suggested by the LPP model. These values have been multiplied by their respective unit profits to obtain the profit per month of each product. In this case where customer orders were not considered, the product mix suggested by the LPP model was Polo, basic Tshirt, Mock neck T-shirts, singlets, and short pants at optimal volumes of 0 , $330,538.4,140,265.7$, 0, and 28,254.43 respectively with a total profit of Birr 499,058.5 per month. It can be shown then that with the LPP optimal solution, the profit of the company can be improved by $7.22 \%(499,058.5$ $465,456 / 465,456) \times 100$. Adopting operational research techniques in the production decision help the company to improve its objective.

Table 5: Comparison of customer order production and LPP values.

\begin{tabular}{|c|c|c|c|c|c|}
\hline \multirow[b]{2}{*}{ Product Type } & \multirow{2}{*}{$\begin{array}{l}\text { Profit } \\
\text { per Unit } \\
\text { (Birr) }\end{array}$} & \multicolumn{2}{|c|}{$\begin{array}{l}\text { Production } \\
\text { Volume/Month }\end{array}$} & \multicolumn{2}{|c|}{ Profit (Birr) /Month } \\
\hline & & $\begin{array}{l}\text { Customer } \\
\text { Orders }\end{array}$ & LPP & $\begin{array}{l}\text { Customer } \\
\text { Orders }\end{array}$ & LPP \\
\hline Polo T-shirts & 5.25 & 15000 & 0 & 78,750 & 0 \\
\hline Basic T-shirts & 4.82 & 35800 & 68576.43 & 172,556 & $330,538.4$ \\
\hline $\begin{array}{l}\text { Mock Neck T- } \\
\text { shirts }\end{array}$ & 4.85 & 13500 & 28920.76 & 65,475 & $140,265.7$ \\
\hline Singlets & 3.2 & 12500 & 0 & 40,000 & 0 \\
\hline Short Pants & 6.75 & 16100 & 4185.841 & 108,675 & $28,254.43$ \\
\hline \multicolumn{4}{|c|}{ Total Profit/Month (Birr) } & 465,456 & $499,058.5$ \\
\hline
\end{tabular}

\section{Conclusion}

Ability to use resources (resource utilization) was recorded as the major constraint in the apparel manufacturing industry. The profits comparison between the actual production and production using LPP models show sizeable differences. From this point of view, it can be concluded that the apparel company should use quantitative research methods of linear programming to determine their optimal product mix. Thus, it will be possible to obtain the following results:

$>$ The profit of the company can be improved by $59.84 \%$ (from Birr 465,456 per month to Birr 777,877.3 per month).

$>$ Denying customer orders and adopting the LPP solution provides only three types of products but the profit of the company can be improved by $7.22 \%$ (from Birr 465,456 per month to Birr 499,058.5 per month). 
Use of an operational research technique in the production time horizon helps the company to improve its objective.

\section{References}

Arefayne, D., \& Pal, A. (2014). Productivity Improvement through Lean Manufacturing Tools: A Case Study on Ethiopian Garment Industry. International Journal of Engineering Research \& Technology (IJERT), 3 (9), 1037-1045.

ETIDI. (2014). Textile Industry Development in Ethiopia. An Overview of Facts and Opportunities, Addis Ababa, Ethiopia.

Ezema, B.I and Amakoml, U. (2012). Optimizing Profit with the Linear Programming Model: A Focus on Golden Plastic Industry Limited, Enugu, Nigeria. Interdisciplinary Journal of Research in Business, 2 ( 2), 37-49.

Kumar, V. (2010). JIT Based Quality Management: Concepts and Implications in Indian Context. International Journal of Engineering Science and Technology, 2 (1), 40-50.

Reeb, J. and Leavengood, S. (1998). Using the Simplex Method to Solve Linear Programming Maximization Problems. Oregon State University, Extension Service

Samuel, S. (2012). Investigation on the Effect of Supply Chain Integration on Ethiopian Garment Industry's Performance. A Thesis Submitted to the Department of Management. Addis Ababa University, Addis Ababa, Ethiopia.

Shaheen, S. and Ahmad, T. (2015). Linear Programming Based Optimum Resource Utilization for Manufacturing of Electronic Toys. International Research Journal of Engineering and Technology (IRJET), 2 (1), 261-264

Yahya W. B. (2004). Determination of Optimum Product Mix at Minimum Raw Material Cost, Using Linear programming. Nigeria Journal of Pure and Applied Sciences, 19, 1712-1721. 